\title{
Business Intelligence Information in the World Under Control
}

\author{
Andres Felipe Quimbayo Gomez, Jhon Alejandro Botero Gomez, Leyder Andres Cabrales Salazar, \\ Jhojan David Reinoso Bernal, Andres Felipe Marín Rodríguez
}

Systems Engineering, National Unified Higher Education Corporation, Bogotá, Colombia

Email address:

andres.quimbayo@cun.edu.co (A. F. Q. Gomez), jhon.botero@cun.edu.co (J. A. B. Gomez), leyder.cabrales@cun.edu.co (L. A. C. Salazar), jhojan.reinoso@cun.edu.co (J. D. R. Bernal), andres.marinr@cun.edu.co (A. F. M. Rodríguez)

\section{To cite this article:}

Andres Felipe Quimbayo Gomez, Jhon Alejandro Botero Gomez, Leyder Andres Cabrales Salazar, Jhojan David Reinoso Bernal, Andres Felipe Marín Rodríguez. Business Intelligence Information in the World Under Control. American Journal of Computer Science and Technology. Vol. 4, No. 3, 2021, pp. 55-74. doi: 10.11648/j.ajcst.20210403.12

Received: March 18, 2021; Accepted: April 8, 2021; Published: August 27, 2021

\begin{abstract}
As a starting point and to clarify the methodology of this project we emphasize that the first person to coin the term Business Intelligence was Hans Peter Luhn, IBM researcher, who, in his article "A Business Intelligence System" published in 1958 mentions the term and provides the following definition: "is the ability to learn the relationships of facts presented in a way that guides actions towards a desired goal". And although it is quite basic compared to today, it opens the doors to a large field of research that brings us to one of the most important technologies of today. Years later topics were introduced to the world of BI, as for example the creation of the concept of database, then large databases for large companies, in the same way the concept of the Datawarehouse, time later arrived the Business Intelligence 2.0, Big data and so on to structure a robust methodology in which all companies worldwide would be immersed. On the other hand, and hand the main objective of the BI was structured. It allows companies to optimize resources, monitor the fulfillment of the company's objectives and the ability to make good decisions to obtain better results. It represents a competitive advantage for the company, since it acts as a strategic factor in its organization and responds to the doubts that arise in a business, such as financial control, cost optimization, customer profile analysis, production planning or profitability of a product. Thus, all Business Intelligence systems have in common the following features: Accessibility to information: these tools and techniques guarantee users' access to data, regardless of where they come from. Decision Support: Users are sought to have access to analytics tools that allow them to select and use the data they are most interested in. End-User Orientation: The aim is the independence between the technical knowledge of users and their ability to use these tools.
\end{abstract}

Keywords: Intelligence, Oracle, Warehouse, Systems, Etl, Corporate, Tools, Logic

\section{Introduction}

This article addresses the phases of information that we find publicly and privately, we also take the differences between it and the types of use BI that are given to it, because this is the most valuable asset of a person or company, it is of great importance to know its meaning and mode of use on the network, so we can know how it is used and stored by large corporations either for statistical or commercial purposes, it should always be stored in such a way that when consulting it is as efficient as possible, if as precisely as possible, this gives an advantage to which it has to predict the facts relating to a future with that data and to get an idea of the measures that should be taken in a given case happens one of the possible scenarios raised at the time of considering them.

\section{Business Intelligence}

Intelligence is a general set of processes, collection methods, applications, storage, and data analysis technologies. Operations or activities that make it easy to quickly and easily obtain data from business management systems for analysis and interpretation.

Traditional originally emerged in the $1960 \mathrm{~s}$ as an information exchange system between organizations. It was 
further developed in the 1980s along with IT models for decision making and converting information data before becoming a specific offering on the part of BI teams with ITdependent service solutions.

Organizations perform business analytics as part of their largest business intelligence strategy. They are designed to answer specific queries and provide an analysis at a glance to make decisions or plan processes.

[1] Business tools have evolved over the years. In addition, the level of awareness, need and evolution of the market have made companies consider business intelligence a priority before management and decision-makers.

Modern business intelligence systems are able to automatically detect threats and opportunities and notify the right user at all times. They consist of sources of information, models, users and technical means.

The main function of the system is to collect information from all relevant sources, validate it, process it and deliver it in the appropriate format to the users who need it.

The information collected by leveraging services and software to transform intelligence reports and business tactical decisions. It acts as a data-driven decision support system that it uses interchangeably with executive information systems, information books, and technology reporting and consultation tools.

All companies use these tools to help them quickly identify information and adapt to changing environments. They help organizations grow by improving decision-making processes implemented at all levels of management.

A strategic factor for a company or organization, generating a potential competitive advantage, which is nothing more than providing insider information to respond to business problems entering new markets, promotions or product offerings.

Data is demoralized to support high-performance queries, while operational systems are often standardized to support continuous data insertion, modification, and erasure operations. You have to translate from one or more standardized and independent operational systems to a single demoralized system, whose data is fully integrated.

Potential benefits of business intelligence [2] tools include accelerating and improving decision-making, optimizing internal business processes, increasing operational efficiency, overall new revenue, and gaining competitive advantage over business rivals.

Increasingly, however, business executives and workers are using business platforms on their own, in part developing self-service and data discovery enterprise tools and dashboards.

A couple of leading vendors defined technology from the start, but suppliers from more traditional companies have followed their path to information data competitiveness. Advanced analytical projects are led and managed by separate teams of data scientists, statisticians, modelers, predictions and other qualified analytics professionals. While business teams monitor more direct business data query and analysis.
Companies can use data features faster and refine or modify development plans as business needs change when new requirements arise to take precedence over previous business competitors.

Intelligence or business intelligence is a business strategy that aims to increase the performance of the company or the competitiveness of the business.

The most [3] effective solutions adapted to the new technological environment prevailing and the needs of the most efficient management company available to many modern organizations who are interested in maximizing their investments in the area of computing.

If a company makes good use of business intelligence, it can serve as a strategic factor that makes it a potential competitive advantage, in order to provide insider information to respond to or solve business problems.

Thus, business intelligence gives us a competitive advantage over those who get lost between unusable or unstructured information from which we can select, classify and structure all that seemingly dissected data flow that new technologies offer us and turn them into truly useful information for our company.

Today it is often not only relevant that information is used, but we can access it at any time without hindering, generating statistics to our coexistence and at once. Rapid data processing will save us tedious and lengthy processes in which to select those that really interest us.

Managing information management, management, and control as a strategic weapon is part of business intelligence, supported by IT and [4] analytics tools that help organizations maximize their performance generated operational efficiency.

There are elements that are highly correlated with business intelligence, as they would be the key factors in achieving what we will later detail as business processes.

The data is the same semantic unit and corresponds to primary elements of information that alone are irrelevant to decision support. It can also be seen as a discrete set of values, which say nothing about why things and are not indicative for action.

Undoubtedly information systems have contributed to business by innovating new ways of developing processes; adopting new technologies in a more digital medium contributing to the transformation of the commercial enterprise and contributing to a more globalized economy.

For directors of companies, managers and similar positions, the contribution that BI makes is crucial; you could imagine professionals in these positions without tracking sales, costs and expenses generated, or worse, without making projections for lack of historical information. Hence the importance of $\mathrm{BI}$ and the information systems that organizations adopt for the development of their business activities and management.

If we ask any executive about the main outcome in the business process, beyond emerging products or services that align with the so-called value chain, businesses immediately definitively base all unstructured decisions present at the 
tatico and strategic level, based on accurate, elaborate knowledge and the use of evolved and technological technical tools intended for this purpose.

By talking about BI we are [5] characterizing a set of processes, technologies and people that has the ability to transform information and information data into knowledge, with the aim of optimizing business decision-making and facilitating management through tracking patterns of behavior and transnationality.

The implementation of technologies with a greater strategic character and less focused on operationality is transferred. It means that people need to be trained in understanding the processes, tool management, and data culture that BI entails, how they can be architects of business transformation.

Today, determining how to handle and leverage information based on its quality is critical for business management to translate into better results, which is why we talk about business intelligence or $\mathrm{BI}$, a process that facilitates the analysis of the data that a company has, to turn useful information that supports business decisions into knowledge.

Business intelligence enables the company to optimize resources, monitor meeting business goals, and the ability to make good decisions for better results. It represents a competitive advantage for the company, as it acts as a strategic factor in your organization and answers the doubts that arise from a business, the control of finances, the optimization of costs.

For companies this that in these tools allow to have full control of the information, in this way organizations can manage this data more effectively in order to understand their current situation, raise possible future scenarios and make smarter decisions based on knowledge.

Its importance lies in the current need for organizations to have cost-effective and effective [6] information for better decision-making regarding the organization's competence. It is characterized mainly by its multidimensionality, because it seeks to synthesize information to highlight the most relevant and by its interest in collective work, appearing as a solution to the decentralization of decision-making in organizations.

Given the importance this concept has taken in recent years, throughout the research different software were evaluated that respond to the needs of business intelligence and contain the necessary tools to achieve a good strategy that ensures success in decision making.

Each of them provides the elements that are recognized as basic when performing a detailed analysis of the information, facilitating and supporting an efficient decision-making process based on the active participation of all members of the organization, who with the help of reliable and up-to-date information will improve the performance and operation of the company.

Something is a fact: business intelligence has become essential for businesses. That's why its importance, relevance, performance, and reliability make information data much more secure.
Data usage is not new, even $98.6 \%$ of companies aspire to a better data-driven culture. That's why today's applications are becoming more innovative and provide insights that can make a company more competitive.

However, as a company grows, so are the challenges. This can cause leaders to lose some control [7] of the rudder and there comes a time when they don't know where to go. Not knowing the right path can bring big problems to the future of the company.

Features include information accessibility, decision support, and end-user guidance. Through intelligent tools, you can analyze data, create reports, graphical maps, and summaries to provide real-time value information.

In addition, its use is not only limited to the private business sector, as it can also be leveraged by any type of company or organization that generates data. Whether it's a public body or institution, whatever the case may be, business intelligence helps make decisions more profitable and correct.

Business intelligence not only gives a company a competitive advantage, but also unifies all the data it generates and makes sense of it. This returns to information in a great treasure trove of opportunities that, in addition to benefiting in the present, allows them to learn from the company's past to give it a better future [8]. Its evolution allows to include more processes and activities such as data mining, reporting, reference values, metrics and performance. Descriptive analyses, query generation, statistical analysis, data visualization, and data preparation make it easier for the company to make clearer the way forward.

\section{Business intelligence benefits}

Companies when using Business Intelligence may consider the following benefits:

Increased efficiency: By having data accessible and agile, you can generate value information that can be visualized on a single platform for favorable use for analysis and decisionmaking on time.

Quick responses to business situations: To be able to make decisions in due course it is important to have all the information in a simple way and not waste time in the search for it and consolidation of the data. Thanks to Business Intelligence, quick answers can be obtained clearly and concisely through consolidated reports and data dashboards.

Control of the functional areas of the company: In all areas of the company value information is generated daily and can be obtained in the best way to know trends, project data, analyze scenarios, etc.

Improve your customer service: With the most meaningful and real-time [9] information, customers can be offered higher quality service from order to after-sales service by knowing more about them and their respective needs.

Present information using indicator boards: Having the possibility to create different dashboards for control you can analyze the main data to be displayed without having to review all the information.

The proper use of the tools that Business Intelligence can make a big difference between a company that achieves 
growth and one that does not, between excellent or poor customer service, between efficient inventory management and the loss of money and resources, between the success or failure of the Company or Organization.

Technology is an ally to help Companies - Organizations achieve expected growth and profitability, the combination of the Business Resource Planning System suitable for your organization and the benefits of Business Intelligence are the perfect complement to bring the Company to higher levels of productivity and profitability through decision-making and execution of timely and well-directed actions [10].

Business Intelligence can add value to any business process, creating an overview, allowing teams to analyze their own data to find efficiencies and make the best decisions regarding investment and cost savings to grow the business.

Today any company must consider the proper use of data analysis tools to have every possible knowledge of the organization, in order to remain more competitive in the market.

\section{Decision Making Information Systems}

Today decision-making and information is considered of great importance as they are composite sets of elements interacting with each other in order to support the strategies and activities of a company or business.

At the time of making decisions, we must have the necessary information because it makes it possible to process, store and distribute the reliable information for the fundamental [11] processes and particularities of each organization. They are a business priority to be able to make the right decisions, lower costs, increase productivity and lead to multiple analysis of interactive processes to explore the real information available about an area discovering trends or patterns from which it derives in ideas and the extraction of conclusions from a study system for the research of each company and organization.

As part of the development, a diagnosis of existing processes in the area is carried out, which are operational systems and information management. Research methods are used by providing data, processes and establishment of correlation efficiency in order to produce valid information for subsequent decision-making.

Information has been a vital resource, whose possession on more than one occasion meant success or failure.

Each system has four basic activities (Collection, Storage, Processing, and Distribution). Decision-making processes are aimed at senior executives and people who have responsibility for the organization.

Already known as DSS (Decision support system), EIS (Executive information systems) and numerous expert systems that provide real-time information every day and in a graphical and summary way.

Organizations working on technology without regard to information needs, invest their assets and make their processes more confusing; because they are always based on technology and not corporate goals.

Companies are now immersed in increasingly competitive environments, where valuable information is critical to adopting business strategies that put the business ahead of competitors. They are already constantly generating large volumes of internal information and tasting information in their environment.

Decision-making is the selection of an action course between alternatives, it is part of a process called planning. It is an activity that over the course of the last centuries has gained notoriety for its importance in organizational contexts.

With the advances of computer and telecommunications technology, an [12] organization's data and information are dispersed in many sources and it is necessary to make schematics that allow to collect everything of importance to the business and place it in a simple and clear way available to all users who are the knowledgeable of the business and who can make the most of the detailed analysis of this knowledge for the good of the company.

One of the most essential foundations on which decisionmaking is based in any company is the use of knowledge, this comes directly from the person in charge of making it and we assume that it has the information of the context, the industry and has the ability to select the course of action most favorable to the organization.

For the search for a high competitive level and growth in this sense a very valuable option to grow the value of this important resource is to integrate it and have it available at the right time so that it can be analyzed by decision makers.

Under conditions of uncertainty, multiplicity of factors and criteria and data insufficiency, this type of model allows to process and analyze different relevant variables, facilitating the comparison between options and helping to reduce the lack of information of decision makers.

The success of an organization is framed in the decisions made by its staff, this deserves to process a large volume of information, that it is up-to-date, truthful and complete so that management makes the right decisions regarding its performance and execution. To do this, the organization must employ new strategies every day in order to create competitive advantages.

In this sense, the human talent that develops in the organization has to be subject [13] to changes in its environment with the incorporation of new systems that allow it to be tracked and can process all the information that is handled, so that successful solutions can be given when there is a certain demand coming from the labor market.

When the organization is clear and organized its computational process according to its mission and vision, it is appropriate to enhance the management-focused information system, so that information can be taken from them to meet the goals set by the organization in the right time, for which this system presents particular characteristics that can make the same information system capable of offering good alternatives that support the organization.

Information systems are of enormous importance in increasing organizational capacity in the face of changing 
environments, being a current need to make decisions a little time to be able to cope with the aggressiveness of it, which makes it necessary to immediate the information processed with a great dose of truthfulness.

The needs of organizations are defined by the global environment where they develop, creating the competitiveness between them and demanding continuous decision-making and with the same possibilities of errors if you do not want to place risk the viability of them. This growing competitiveness facing markets today has led to a dynamic environment where the optimization of resources, whether material, intangible, as well as human talent, is an alternative to grant added value and supremacy to those who use it effectively and efficiently.

The times at which a decision is to be made are significant, since through them a particular problem or situation is studied that is valued and considered in depth to choose a more appropriate path to follow according to the different options and operations.

An organization uses information strategically to perceive changes in its environment, create new knowledge to innovate, and make decisions about its courses of action where information is a key element as [14] "strategic decisions have important implications for organizational performance and are often the result of actor engagement from within and outside the organization."

These particularities are informational in nature. Risk and uncertainty, as well as informational overhead are related to the quantity and quality of information used in the process. In this sense, the information sought and analyzed in the decision-making processes is decisive, adding to the variety, access and interpretation of internal and external strategic information sources.

A computer system that supports the decision-making process which involves the use of data and models for the generation, estimation, evaluation and systematic comparison of alterers, helping decision makers to gather intelligence, generate choices and make decisions.

Today the information has become one of the main resources in which management has focused, because depending on its veracity and reliability it will bring results of great benefit to it, in terms of decision making that will impact the organizational and financial part of the organization. In order for this to be achieved, there needs to be an adequate management information system in which the different subsystems in which the information is to be classified are grouped, so that each of these, provide senior management through various processes with the necessary elements to make the most appropriate decision that goes to the benefit of the organization throughout its organizational environment.

The cooperative system decision support system collects data, analyzes, and then lends itself to a human component, which can then help review or refine the system. [15] This means that a human component and computer work together to find the best solution.

The organization should establish data-driven decision- making as the norm. In other words, you must create a culture that promotes critical thinking and curiosity. People at all levels engage in conversations based on data and develop their knowledge of data through practice and implementation. This essentially requires a self-service model that gives people access to the data they need, as well as security and governance. Skills are also required through training and development opportunities that enable employees to gain knowledge about the data. Finally, having the support of executives and a community that supports data-driven decision-making will motivate others to follow the same path.

With modern business intelligence, organizations are getting closer and closer to understanding the value of datadriven decision-making across roles and departments. These organizations effectively leverage the value of their employees and their data.

Digital transformation has brought with it a number of challenges for companies and the current situation has accelerated digitization, as many businesses, both large and small, had to see the need to make drastic changes in their organizations to continue to function optimally they must adapt the systems [16] to be able to work remotely or make strategic decisions in record time to know what the next steps would be.

Among the great innovations that exist, there are technologies that can support you in leveraging the data generated by your business. Also, to automate complex tasks in order to increase the productivity of all your tasks and workers, as well as look for better sales opportunities. We mean information systems and below we will provide you with all the information you need to start adopting the one that best suits your business.

Organization managers should motivate their employees to manage information appropriately, seeking benefits from lower levels of the pyramid that result in improving the quality of life of all members of the organization. It is a priority for companies to assume the implementation of GIS for the availability of real-time information, this will enable rational decision-making.

Management Information Systems (GIS) are all related and organized procedures that help company managers, regardless of size, make decisions. All levels of the company (operational, knowledge, administrative and strategic) are applicable. They help improve the implementation of information technologies, generate competitive advantages, greater profitability and more efficient business processes because they go hand in hand with automation.

Any company that implements GIS pursues operational excellence, eliminate distances, meet new products and business models, good customer and supplier relationships, enhanced (rational) decision-making, competitive advantages, and survival in a globalized world. GIS contributes to increased corporate value by increasing return on investment and strategic position.

The company's senior management must prevent the following negative impacts from the implementation of GIS, in order to ensure the obtaining or growth of value, 
elimination of jobs by automating the activities previously carried out by people, violation of privacy through the possibility of organizations collecting personal details of people, affecting communities by system failures that may cause unemployment of companies or transport services, repetitive stress damage, technical stress and other health problems in users who intensively use GIS and distribution of illegal copies of software, books, articles and other intellectual property over the internet network.

The appropriation of information systems for support in decision-making in companies going through the understanding of a simulation model developing with system dynamics and a serious video game are framed in the doctoral work entitled "mythological strategies for the appropriation of information systems for support in decisionmaking, support in dynamics of systems and video games. In order to meet the need for technological tools to facilitate the management of enterprise systems.

The need for information from economic policy advisers for [17] decision-making in economic policy and monetary policy by the central bank was returning and being able to define recommendations in this area is increasingly demanding.

Indeed, specialized information is the most important input to achieve goals, provide better services, increase profits and minimize risks in an increasingly complex and competitive world.

Providing the information to those who correspond to the right time has become an important requirement for all decision-makers and the senior authorities of companies are an exception, even though entities par excellence produce information.

Today the information has become one of the main resources in which management has focused, because depending on its veracity and reliability it will bring results of great benefit to it, in terms of decision-making that will have an impact on the organizational and financial part of the organization.

In order for this to be achieved, there needs to be an agreement management information system in which the different subsystems are grouped in what the information will be classified, so that each of these, contribute to senior management through various processes the elements necessary for the most appropriate decision to be made that goes for the benefit of the organization throughout its organizational environment.

The management information system will provide classified information of vital importance to the organization, with the purpose of providing short-, medium- and long-term solutions depending on its raison d'e age, this being a basic necessity for any situation that arises and also bearing in mind that today the competitiveness established in the labor market deserves strategies to be established in order to be able to meet the objectives for which it was created.

Information management is one of the modern tools to facilitate processes within organizations, especially decisionmaking. In the health sector, given the importance of naming the latest developments in essential practice, it is essential to ensure proactivity in meeting the needs of patients, family members and other stakeholders.

Due to the increasingly dynamic creation and dissemination of internal and external information of organizations, it is imperative that these managements in the way they generate, manipulate and transmit information, becoming the raison deer of information and knowledge systems.

In the specific case of the health sector, information management is essential as part of the professional model, which should base its action on the search, evaluation and application of technical scientific information related to human health, in the search and active collection of information using information and communication technologies.

The information structure of organizations must provide flexibility and dynamism to facilitate the efficient flow and exchange of information, this being understood as "sufficiently sized network, easily accessible, cheap and open citizens and organizations", being associated with the term information economy, which however or sufficient unless by the intervention of the phenomenon of information culture.

The information and knowledge management system should aim to identify and implement innovations that optimize the administration of health organizations, especially their environment where the needs of the population often exceed the operational capacity of institutions and the legal and ethical regulations are increasingly strong, among other imperatives.

As a result of the probability [18] levels of occurrence of the hypotheses discussed above, the most likely scenarios in the relationship to information management were achieved as a decision-making tool in health organizations. This is how the scenario where none of the hypotheses occurs is valued by the experts as the most likely.

This may be the result that the application of methodological tools that elevate the culture and awareness of the use of information systems in health entities to achieve information is still recognized as a useful information resource for the development of the organizational intelligence of collective management bodies and influence the scientific quality of the decision-making process until it becomes smart entities and publish their results in impact magazine.

By way of concluding that the most likely hypotheses for the future relate to the fact that adequate tools and platforms exist and information management is integrated into the other processes of health organizations, being in turn the most influential over the rest; while information is handled as a critical resource by facilitating the innovation process, it is more unlikely and dependent.

The combination of hypotheses resulted in the likely scenarios as part of them most likely to occur the experts considered the image of the future where none of the evaluated hypotheses will be performed. This expressed the need to streamline the policies of the business sector so that 
information management had the necessary and appropriate bases (systems, platform, trained human resources and others) to become an effective decision-making tool.

Information systems in companies are an indispensable part of today's organizations, not only occupying the operational part that sustains the day-to-day activities of companies, but also can be used to make management-level decisions.

These systems are a set of software, hardware, telecommunications, database and by their position the human resource. Information systems can be classified into three large groups (transactional, administrative, and decision-making support). We are interested in the latter that belongs to the umbrella of business intelligence applications.

A decision support system is a BI tool focused on analyzing an organization's data and that allows to solve the limitations of management programs, since it has quite outstanding features, such as "dynamic and flexible reports", ease of navigation without the need for advanced technical knowledge, availability of historical reports, user profiles and above all a greater alternative to perform assessments, risk analysis, and even create simulations that allow the administrator to know the impact of their decisions.

On the other hand, the approach to the organizational procedure focuses on the analysis of communication channels, the formalization of processes and the distinction between formal and informal structure. In the company there are individual people who have their own objectives; these people can be grouped together in a way that shares common goals. Therefore, there are multiple different objectives of cariz in the company. In this context, standard procedures, simple rules and feedback are followed to avoid uncertainty. You typically choose the first successful alternative and do not continue to discuss the other alternatives.

There are different approaches that have studied the decision-making process [19]. First, being the ideas of Simon (1980), the figure of the rational decision-making is defined. In this case, the possible alternatives are identified and listed, the consequences of each are analyzed, and those consequences are valued and compared. As for the devisor, you must write your useful function, that is, your preference for different consequences.

A decision is the choice of the most appropriate alternative among several possibilities in order to achieve a desired state, considering the limitation of resources. The word decision derives from the term decide which means cutting; to the current concept, it is understood that a finally chosen alternative is "cut".

Stages in the decision-making process

We consider decision-making to be a process because a series of stages occur sequentially over a period of time.

Intelligence phase: It consists of identifying and defining the problem for which a decision is intended to be made. First, a full internal and external analysis is performed to find the fundamental source of this problem. We must take into account that this analysis depends on how the decisor perceives the problem, i.e., selects, receives, organizes and interprets information; it is necessary to collect all available data about the problem to optimize the usefulness of the information. At this stage a number of quite common errors can happen. For example, we can get an appropriate answer to the wrong problem [20]. In this case, we need to re-analyze the problem, which will remain unsolved. It is also possible to make an unwelcome decision or a decision that does not lead to action. These errors are caused by a lack of organization that involves the use, intuition and not more scientific methods in the decision-making process.

Design, modelling, or conception phase: All possible alternatives, strategies, or avenues of action are identified and listed. To do this we must take a thorough analysis of the problem, being advisable the opinion of several people with different points of view, so that they cannot unused alternatives.

Election phase: It consists in the choice of an alternative, for this all lines of action is guaranteed taking into account the concordance of the objectives of the company and the resources. In addition, the chosen alternative is to be feasible and contribute to the resolution of the problem. It is necessary to take into account the possible future problems and the consequences associated with each of the alternatives Of course, this choice is made based on the quantity and quality of information available to such affection.

Implementation phase: The actions that come with the chosen alternative to solve the problem are developed.

Review phase: It is used to check if the implementation of the decision is the most appropriate and if the desired results are achieved. A check is performed by evaluating past actions, and if something is not correct, the decision process is restarted.

\section{Data Stores}

With the daily exponential growth of the amount of information in all fields known worldwide both social, economic, political and scientific among others, information management is one of the most important areas and has been carried out through databases over time, however due to its growth new technologies have been required for greater efficiency when generating a search in a data store containing millions of bytes of information [21] which is the measure to calculate the minimum amount of this.

When searching for a data in a very large information store requires a longer time, because there are both documents, as well as audios and videos, this makes the well-known search engines slow down in a normal environment.

From the moment we realized that this was falling short of handling larger volumes of information, work began on how to improve those response times by implementing Hadoop, non-sql databases, Map Reducers which are specially designed for use in data storage environments and improve user response with greater time optimization, however this has also led to the need to improve storage components, requesting a much more efficient performance and response with new technologies and specialized software for this. 


\section{What are data warehouses or warehouses?}

when we talk about data storage or data warehouse, we are referring to a system used to create report and at the same time analysis of the data it contains, these data may be located on different geographic sites and may not necessarily be or contain the same structural order.

The data warehouses were developed [22] in order to allow to transport or transmit a large amount of information billions of bits that we find stored in different places so that the end user is people like you esteemed reader or as me, was a more complete search and in turn in a shorter time [23], is technology what you do combine the stored data and look for relationships between them or coincidences so that at the time of generating a search can show all the related words or data and that the client or user can make a decision in a shorter time what will optimize the resources each and every one of those that have access or must make continuous use of it for an optimal development improving [24] every day and allowing the acceleration of the economies and income of dependencies on the Internet of things.

Some of the main advantages of this system, is that we can offer better data, this data is better because of its quality, since those can be collected from different sources, carrying with them a much faster and more efficient response so that in the event that some extraordinary speed is required this system can also respond to you in an extraordinary way, but there is one thing we must be very clear about, and that is that data warehouses are not databases, unlike databases, data warehouses, what they do is a consolidation of data processed and stored for analytical purposes which leads to the formation of large data sets, which have a logical order for their reading and interpretation, also being interconnected with different databases makes the information always more up-to-date more truthful and so we can make the most accurate decision possible depending on the area in which we are going to implement it with almost zero margins of error in most of the time, we must bear in mind that in turn there are data lakes which are not considered data warehouses since these are stored in large volumes but are not organized in such a way that they cannot be generated analysis and in some way is not a data Mark since the data warehouses are not limited to a specific information or yet its set nor is it made for a specific user, company or entity of any kind or nationality, since this absorbs all the global information for the most up-to-date and stores it but in turn also makes it available to anyone who requires it regardless of the time in which it is located worldwide in a given instant.

It is believed that data warehouses with a not too distant time will become one hundred percent data in the cloud as it offers in greater flexibility when handling them, taking also into account that being in the cloud and if a storage service is paid to the data warehouse, this service would be generating economic savings given that the software and strength, they have for mutual benefit would be reducing administration costs as they would become an external entity that is to say who rents the service or provides the service and with it being an external entity, also provides more comprehensive guarantees than if we were in our company, having as added value the fact that by offering services this efficient has highly qualified staff when it comes to managing and consolidating the necessary requirements for successful operations and satisfied and calm customers or users of their data in safe places.

in order to be clear that it is a data warehouse we must know this does not replace the information, that is to say that the information stored there will be permanently this only indicates that everything that we upload to the network will be in it permanently but the main function of this part is the help to make the best decisions based on statistics with optimization of results in real time either specific location or a variety of them and that each new bit that is generated will be captured and stored forever making it extremely useful over time, since these remain in the history of the day to day with impressive accuracy.

In many companies they benefit from all this information stored by internet users regardless of how we connect to it, be it social networks, emails, searches, chats; among others. Since they analyze it to offer us a service or product according to our needs based on it mainly searches in the different engines such as Google, Yahoo, Bing among others, engines that keep a history always give the possibility to observe the daily life of each one, their habits and the possible needs in certain periods of time.

Data warehouses have basic structures [25], which provide raw data and are stored with metadata, a test where data can be used to test and then be stored, currently data stores and data not repeated as surveys comments conversations emails chats, are treated in a different way since these data are more sought after by advertising companies and they use these services to give them a greater advantage over competitors in offering products or services [26].

For data warehouses, cloud is very important because it has greater agility, global localization, and price control, much more accessible to anyone or company that requires these services; In terms of agility refers to the economic point of view we know that all companies want to have information about their users, as a very recent example we can take to Facebook, WhatsApp and Instagram which monetize all this information by bringing to the customer an ad service or advertising specific to the searches you have made on the different current platforms, taking also a reading of the mail I have had with another person where I mentioned a certain product or specific word, This makes companies have a much higher profit as they reach all audiences in less time and in a determined way to advertise to more potential customers generating profits on a large scale.

Localization is also very important one because they can be made from anywhere in the world and two why you can access a topic specifically at a much more efficient speed than you would in a general search as these data are entered and ordered for the efficiency of data consumption in the network then we could mention some very marked advantages such as massive monetization, information protection as being in the cloud will always see additional 
backups in case the main information fails enough consolidated and a single package for a much more stable efficiency from all directions and at all times.

it is necessary to bear in mind that the data warehouses can be confused e some cases with big data but this has a marked difference since the big data is called a lot of varied information and that can grow exponentially continuously and are structured data in addition to this data can be from business environments only having certain restrictions when accessing a user outside this entity, company or corporation, but which complement each other since data warehouses have specific information in a historical way and big data collects that information for corporate or corporate benefit mainly while data warehouses consolidate information from all sources, seeking as much precision as possible so that those who use this information have sufficient time to make a decision on it and as much time as possible to save, which was not possible a few decades ago because such technology was limited and expensive compared to what it is now; among these components of the data warehouses it can be said that they look for as much data as possible to take them to the cloud making it much more cost effective economically speaking and in turn much safer in terms of responding to disasters and so on owners. These data stores have several architectures or structures that when implementing their use among them was the payment of those operations.

By making use of it they may contain few or many data sources or sources of local information, more efficient, in the data stores there must be layers necessary to be able to contain all the information and that this is as efficient as possible between those layers we have the source layer, data extraction layer or test area, etl layer, storage layer, data presentation layer, metadata layer and system operation layer.

All of these above are necessary in order for them to influence efficiently, all this stored information will enter and be consulted by users, without them it would be very difficult to have an efficiency as you did so far in going to consultations on certain topics to make certain decisions based mainly on the contents of it and the statistics that emerge from it.

For this it is necessary to take into account some main properties which are:

Separation, this allows the process of analysis of that data to be done independently of the transaction process of the same

Scalability. this allows both the software and the current hardware have been updated to be able to satisfy the queries made by users

Security to be aware of access to important information stored there

Extensibility allows new technologies to be integrated, applications without having to make a modification to the rest of the system to work together.

Administration which is essential for the active operation of each and every component that belongs to it directly and indirectly also hardware, in the layer of data sources are handled formats that can contain information no matter what equipment is for operations data are taken into account human resource sales and inventories and what is advertising or marketing is related to data from user navigation the research that can be done internally to improve the quality of the same and the data of people independent of it and which can enter the surveys that in one way or another also allow to make decisions based on the information containing.

Data warehouses have a very important layer called etl which is nothing more than the expression extraction, which is responsible for taking it first-hand and making use of it in such a way that it can be said to be a clean-up of every bit that is generated in the network, After this process comes the second stage of the system and it is the transformation that takes care of taking those extracted data and taking them to the optimization point to be used by the system in the most convenient way taking into account that each type of data is variable from others and that its content may or may not apply to different options and finally the location is what it does is to allow the user to be dimensioned much more efficiently to the most accurate information [27] according to their search in the system also having a storage layer takes are search data and links them to the clean information on them, this location is always accurate for search engines since it is already organized in such a way that its use is always instantaneous. once the system has consulted this information through the different channels that it presents to the end user either in text or through graphics in the browser or in the different ways in which it can be consulted, for them, the use of the metadata layer and the system operations layer are combined as they efficiently access the history of the census of users and the location of the census so that they reach the end-user in the shortest possible time [28].

Looking at the above can be considered the following which is made mainly for corporate environments and that for the end user only a part of that information is perceptible through the search engines in each of them that we do is daily through the different devices have already behaved hours' cable cell smart devices among others.

We can also say that the main objective of data warehouses is to help you make decisions in an area that can be political economic social or educational and generate more truthfulness in the information we have available to generate queries on certain time and space.

We know that the power of this tool [29] is extremely high because quantities can be measured in trillions of bits and in these trillions of bits both public and private information is kept and there is also some of that information catalogued by governments as classified which is not accessible to the public since it is managed only by governmental entities which require explicit permissions to specific users in specific times and sites taking into account the above can be said that data stores are part of the day-to-day digital age, retaining a historical footprint of what has been the evolution of science and information [30] and thereby leaving many of the old working and storage models gradually obsolete, whose useful life will only be conserved over the years as 
something historical and revolutionary in its time, in other words it is so fast in advancing technology, almost exponential that in a few more years, systems that are still in use will remain for historical data queries, and not because they are not yet useful, but because for speed requirements they will no longer be suitable and their use is linked to a long time by then, luxury that no one can afford when making important decisions in the not too distant future to our day.

\section{Database Management System}

Before the appearance of database management systems (by the seventies), the information was managed with the typical and simple file management systems that were managed on an operating system, these consisted of a set of programs that defined and worked their own data, if some of the files changed it was necessary to modify all the programs that managed them.

Normally different devices are used such as hard disks, floppy disks, USB flash drives among others, these devices are known and characterized by being slower than the main memory of a computer or normal computer, but also has a limited storage capacity, and are not volatile, to give more context do not lose their content and information to be disconnected from a computer or computer, but to save or store information on these devices is necessary to group and organize them into files or files.

A Database Management System [31] or Database Management System abbreviated DBMS, is a system or software that help us to manage and administer the information contained in the databases, through the database managers is handled, manipulated and administered all access to the databases in order to help with an interface with which interacts between the user and applications.

Mainly database managers control any activity performed by the user in the databases, but we must take into account the difference between a database manager and a database.

A. What is a database?

Databases are a set of structured and unstructured data that is sorted and stored like for example a library which is a set of ordered books and documents from which information is queried, databases work in such a way that data can be obtained when required, databases can contain many types of data such as, for example:

Numeric data, such as decimals, integers, imaginary numbers among others.

Data such as character strings

Alphanumeric data

Date type data, among others

Already having clear the difference between a database and a database manager let's go deeper on the topic of database managers.

$B$. What are the components of a database management system?

A database management system is confirmed by several components, all of which contribute to the proper functioning of the system or software [32], the basic elements that make up the database managers are the following three, the data dictionary, the data definition language and the data manipulation language.

Data dictionary: It consists of a list of metadata that shows the characteristics of the different types of data included in the database, as well as information about the permissions of each record and its physical representation. In this way, the dictionary provides all relevant information about the stored data.

Data definition language: The data definition language, also called database language or DDL (data definition language), works to structure and organize the content of the different data stored in the database. Thanks to this language, it is possible to create, modify and delete individual objects also known as CRUD, such as references, relations or user rights.

Data manipulation language: With the help of the data manipulation language or DML (data manipulation language), new records can be added to the database, as well as delete, modify and query existing records or objects. This language allows data to be compressed and extracted.

C. A database manager must allow:

Structure a database, specifying types, structures and data constraints.

Create a database to store data by a database management system.

Manage the database to perform queries, update data, generate reports and reports.

\section{Database management system functions}

Database management systems handle three important elements, the information, the database engines that control and manage the information, and the database schemas, which define the logical structure of the databases, these three elements are essential to ensure the security and integrity of the data, as well as in the administration procedures.

Thus, the main functions of database administration supported by database managers provide change management, monitoring and recovery.

A term used to summarize the transfer and transaction functions and properties of [33] database management systems is ACID, which stands for Atomicity, Consistency, Isolation and Durability, these concepts encompass the most important requirements of a database manager.

Atomicity or integrity explains and describes the "all or nothing" property of database managers, whereby all transfers and transactions must complete completely and, in the order, indicated to be valid.

Consistency implies that completed transfers and transactions will not affect the stability of the databases, so it must be monitored frequently.

Isolation ensures that transfers and transactions do not hinder others that usually handle some locking functions.

Permanence implies that all data is permanently stored in the database manager, not only after successful transfers and transactions, but also and especially in case of any error or 
system crash.

These are some of the various functions and properties of database management systems, which go beyond the ACID model

Data storage: The database stores text, documents, passwords and other digital data that can be consulted.

Data editing: Most databases allow direct editing of stored data, depending on access rights.

The database stores: The documents, passwords and other digital data that can be consulted.

Data deletion: The records contained in the database [34] can be completely deleted. In some cases, it is possible to recover the deleted data, while in other cases the information is lost forever.

Metadata management: In the database, information is usually stored with metadata or metatags, which, for example, help to organize it and facilitate the search function. Data management consists of four fundamental operations: create, $\mathrm{read} /$ retrieve, update and delete. This concept, known as CRUD.

Data security: The database must be secure to prevent access by unauthorized persons. To maintain data security, in addition to implementing an effective encryption method, the database must be carefully managed, especially by the main administrator. Above all, maintaining security is based on taking the necessary technical precautions to prevent data from being lost or manipulated, which is a central aspect of data protection.

Data integrity: By integrity we mean that the information contained in the database adheres to certain standards to ensure its consistency, as well as defining its business logic. This is the only way to ensure that the database as a whole function consistently and coherently. In the relational database model, four of these rules apply: domain integrity, entity integrity, referential integrity and logical consistency.

Multi-user mode: Database applications allow access to the database from multiple devices. In multi-user mode, it is essential to properly distribute rights and maintain data security. Another challenge for databases with this feature is to maintain data consistency when many users query and edit the data, without affecting performance too much.

Query optimization: On the technical side, the database must optimize the processing of each query as much as possible to ensure good performance. If the database has to "spin up and down" to query the data, the overall system performance will suffer.

Triggers y stored procedures: These procedures are handled by mini-applications stored in the DBMS [35], which are automatically activated (triggered) as a consequence of some actions, with the aim of improving data integrity, among others. Triggers and stored procedures are typical relational database processes; the latter can also contribute to system security if the user is only allowed to perform actions through predefined procedures.

E. Popular types of DBMS

These are some of the most popular database models and their management systems:
Relational database management system (RDBMS), suit most use cases.

NoSQL DBMS, ideal for loosely defined data structures that may evolve in the future.

In-memory database management systems (MDBMS) have fast response times and better performance.

Columnar database management system (CDBMS) is a good choice for storing data that has a large number of similar data elements.

Cloud-based data management system, is a cloud service provider is responsible for providing and maintaining the database management system.

Of the numerous database management systems, these are some of the best known and most widely used.

1. Cache

2. CouchDB

3. $\mathrm{Db} 2$ de IBM

4. Firebird

5. IBM Informix

6. IMS de IBM

7. MariaDB

8. Microsoft Access

9. Microsoft SQL Server

10. MongoDB

11. MySQL

12. Oracle Database

13. OrientDB

14. PostgreSQL

15. Sybase ASE

F. Relational Database Management Systems

The relational database manager model is the most used in the administration of databases, since it consists of establishing links or as the name says, to relate between the data storing the information in tables with the different types of data.

The relational database manager model uses the structured query language (SQL) [36].

The relational database managers most used by the different information systems are:

1. MySQL

2. SQLite

3. PostgreSQL

4. SQL Server

5. Oracle

6. Microsoft Access

G. Non-Relational Database Management Systems

Unlike relational database managers [37], these databases do not require a fixed structure in their tables.

Some of the most commonly used non-relational database managers are:

1. MongoDB

2. Redis

3. Azure DB

4. Cassandra

5. DynamoDB

H.Advantages and Disadvantages of a Database Management System 
Database managers provide us with several advantages and strengths such as:

1. Data abstraction and independence.

2. Data abstraction and independence.

3. Easy and efficient access to stored data.

4. High availability

5. Simple access through an application programming interface.

6. Robust data integrity capability.

7. User access control (security and data protection).

8. Rapid recovery from crashes and errors, including restart capability and resiliency.

9. Efficient handling of multiple application needs using the same data.

10. Data management procedures.

11. Activity logging and auditing.

12. Data security.
13. Easy management of large data sets.

But like all good things, database management systems have some disadvantages.

1. Less efficient for special software.

2. Requires qualified employee for the control of this (Database Administrators).

3. Vulnerability due to the fact of centralizing the data.

I. What Is a Database Administrator?

A database administrator is a professionally [38] trained person who is in charge of the administration of information and communication technologies, besides that is responsible for managing the different types of database managers where he generates queries or queries to obtain information [39] in an organized manner, is also responsible for managing the permissions and users who have access to either query, record, modify or delete information in the databases [40].

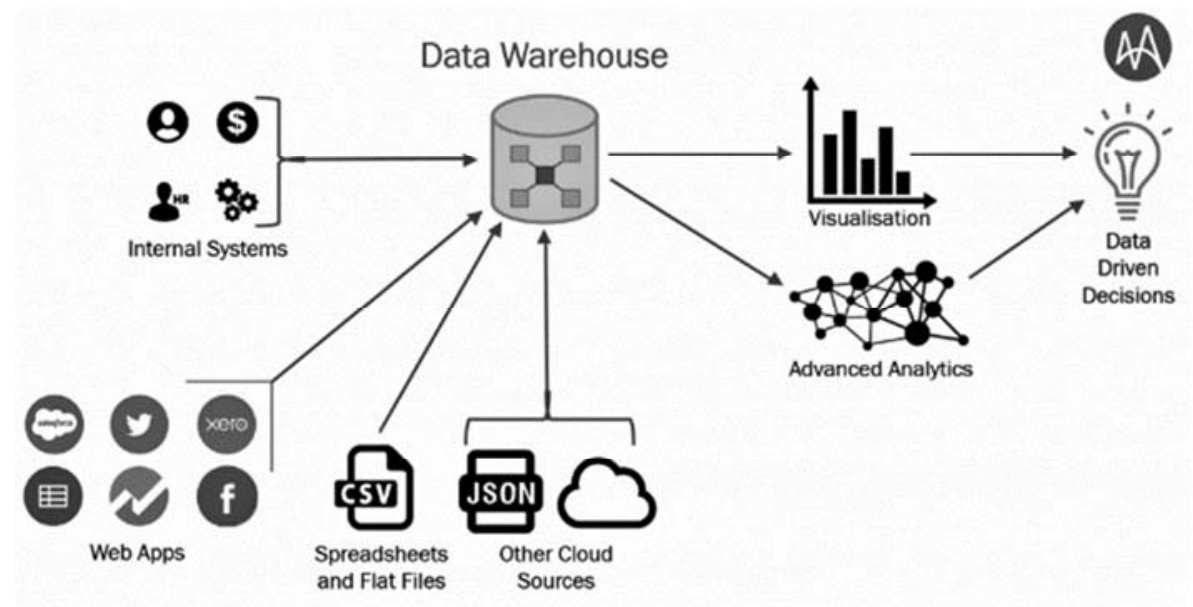

Figure 1. Data Warehouse.

\section{Data Warehouse Layers}

The Data Warehouses system is a data warehouse, which is specialized as software to analyze data that is supplied in it. This software has internal and external information sources, which are used to perform operations necessary to obtain important knowledge in the user and thus can make decisions based on an excellent and developed analysis in the information.

In the Data system are small base units, to store information according to the criteria that the company or business has. They are named as Data Marts, which contain the analysis of a specific area as required and will be information criteria linked to each other, such as having several departments of the company and distributing them in terms of needs and organizations; within each large Data Warehouses system there will always be subunits of Data Marts.

Each Data Marts subunit has the ability to perform its own updates and organizations on the information data it contains. The data managed by each subunit can be consulted by the OLAP tools, which are required to analyze the rest of Data Marts and have an overview of each.
There are several components that make up Data Warehouses systems, each system with the information, will be sent to an integration layer where data will be loaded (ETL) and will have a transformation for the need of the company or business. The data will then go to the presentation layer where it will be analyzed and have an orderly processing followed by indications given by the administrator in charge of establishing it, it is in the Data Vault where the information data will be stored. The last component where the information is handled is where the content is separated depending on the different functions to be performed for the company.

Data Warehouses has several applications [41] for the business or company employed, these are: market prediction, behavioral analysis, cost modeling and budgeting. Each of them gives us a clear vision of the actions that we can employ with this system, promoting a good management of the functions performed by each department or specific area of work and business study.

Market prediction gives us the privilege of predicting a market's flow based on historical information, to conduct proper research to detect patterns over time. In this application you can manage future risk situations so that you 
can manage the problem with strategies.

Behavioral analysis in the Data system promotes research into the behaviors of customers that the company has, classifies business behavior according to the study criteria in a given order and with specific information about each of them.

In cost and budget modeling we can make use of functions that allow us to add and group information. Based on this, the costs acquired by each operation carried out are analyzed, in such a way that improvements in the business are promoted for its evolution in the market.

The system offers us benefits for the proper functioning of business information, taking into account its customers to be transformed into an appropriate knowledge of the company to establish new strategies. In the benefits that are obtained in the system is mainly the quality and consistency of information provided, and the speed of response which is necessary to obtain concrete and immediate reports.

There are processes in companies and businesses where they use representations to observe data warehouse information, visualization is a key model for a better understanding of the processes that the system performs; this becomes one more benefit of Data.

In the context of Data systems, there are two types of architectures that are proposed by Bill Inmon and Ralph Kimball with two different thoughts versus Data. Top-Down is that architecture where the system is built from a complex level to a single level level; then there would be the Bottomup proposed by Ralph Kimball, resulting in the system having to be built and developed from simple levels, to build complex levels tailored to time. In these two proposed architectures you will notice a big difference due to the order they have and the way the Data system is made.

To design the system as dictated by Inmon, it is necessary to have the Data as a central unit and structurally with all information relationships bound to the Data Marts, where all possible data is defined at a start. All that source of data, which provides truthful and important information to the company or business, needs to be extracted to have concrete and manageable knowledge for it. A relational model, based on the integration layer, is then developed so that the information is transformed into a normal third form where the information data is normalized and will have a finished process for its handling.

Data Marts will be built after having all the general information [42] with their respective standardization by the integration layer, these will promote the classification and order of the acquired information, where reports and reports will be presented as the basis for analysis.

Inmon gives rise to certain features that are necessary for a Data Warehouses, which integrate the basic needs for its operation and in turn the understanding of the different processes that leads to better performance of specific information results. The features will be presented immediately according to the architecture model proposed by Inmon.

The system has to be oriented to a topic, because it is necessary to have the clarity of all the concepts and generalities of it, to develop strategies that with the help of Data can have a growth of the business and thus constitute an evolutionary progress in the market in which it is located.

In the history of a business, situations that can affect it severely are evident, and thus have a weakness for its continuation in the market, so that as a criterion in the system according to Inmon it is vital to observe the time variants in the business, since the information presented is the same and actions will be taken according to what is obtained. It will be non-volatile the information to be permanent and persistent with the historical one, which will do a lot when it comes to reusing old measures carried out without loss of information.

All company information will be integrated into the system so that areas are specifically related and immediate analysis, reports and reports can be performed for control and verification.

In the architecture proposed by Ralph Kimball, a modular design is made, in which everything will have its process of start and complexity over time, taking into account the criteria necessary for its safe progress. For the creation of the system as mentioned Kimball is required to have the subunits Data Marts, to organize all information according to the specific areas that the business has and then make effective connections with each other.

A "bus" will complete the Data, which is a means by which the different subunits of Data Marts are integrated as if they were working as a single unit throughout the system, which guarantees a classification and order of the information fully related to develop the processes or actions that the administrators of the company want to resort to.

From the operational systems and applications of external means, the sources of information are obtained for their respective order and entry into the procedures required, in order to achieve maximum performance in the use of information. Each area in the Data has the responsibility to update and organize its information according to the needs required by the company, taking into account the knowledge of the largest customers they have and thus perform standard models that allow strategies of improvement in the market.

Ralph's architecture takes time; however, it does an orderly procedure with effective performance in terms of the immediate analytics your company needs. The structure it models is duly understandable for those who come to use this architecture as a strategy of a better and fast analysis of information, obtaining from each area necessarily what is useful in terms of the market work, customer need and knowledge in competition.

The system as raised by Ralph is appropriate in the maintenance of each department, since they are themselves in charge without using more resources than are needed, and they are the Data Marts who manage the appropriate procedure to carry out this work [43].

The structure is based on a dimensional model, which takes into account the ease of reading, representation of information visually for the user who analyzes it and presentation schemes of each data used for a transformation 
to knowledge appropriately.

In contrast to the two types of architectures, you can get a clear view of what is appropriate to run the system and contribute to efficient information management for operations, analysis and distribution of content to the areas of the company. In conclusion, the structure formed by Ralph Kimball offers a greater benefit in terms of system processes and an ease of reading the procedures required for the investigation of all the information presented in the labor market, analyzing the interests of customers and developing new business strategies for the future that the company may have.

Queries in Kimball's Data system are fast and responsive, when reports and reports are required based on information gained over time. The main advantage of following this model is that there is an update by each area, that is, each Data Marts to have more consistent information.

The design of the Data Warehouses system is developed through Kimball's architectural model, for its modular ease in view of the companies and the important bases it has to organize its information.

The place where the data is represented in the system [44] is known as the dimensional model, which contains a format with symmetry in performance and efficiency to perform queries, resistance in organizational changes and information that is made according to the needs of the company and, finally, the ease of understanding it offers us; because a program with complex tools represented with simple formats is required to manage.

The dimensional model has two important components for its use, which are two tables, one and one of dimensions.

The component with the fact table, represents quantitative measurements of the business, with which we can do operations because they are numerical values and that according to the data that are obtained in the business mathematical calculations are made.

Fact tables do not contain primary braces for linking to others, but are made up of foreign birdshot their dimensions; they complete many-to-many relationships based on the amount of data they contain.

Dimension tables are those that will accompany those of facts, which is where the data is obtained from.

Because Data Warehouses is a system for a particular business area of a company, it will require an information organization to be integrated and with variations in time, since it is necessary to have history of each event that happens through the company, however, it is necessary to store everything to be able to make decisions in all areas of work. To create this type of system it is necessary to have your office program and tables that contain the information to use throughout the process.

The program is named SQL Server and it will provide us with all the tools from its interface; the specific system is a database that gives us the option to organize our data tables to create specific information in what the company requires.

To query from the program, it is required to always have tables from each workspace full of data; the tables have to correspond to the entire company. Developing [45] the process from the program is a requirement of the information previously provided, so that there are no delays in the establishment of the database.

Creating the Data system from the program offers us the possibility to make various queries and always verify the contents of each table, the name mapping for your organization and the respective research in each area of the company.

From the tables that are contained in our computer, we can perform the Data system with any table you want, which is a benefit to make many queries from various.

Creating the database in your requirements is always necessary dimension tables with their respective attributes, which will be used later to make their relationships. A fact table is also required to observe month, year, or sales amount characteristics for a company that needs to gather all the sales scopes of its products, each with its unique reference. In the event that a dimension table is connected to the main fact table with different business processes in the company, it will be known as "Formed Dimensions".

In the program, you must deploy the ETL to integration services, where your data is transferred from the primary database to the Data Warehouse. Entering all features in each of the tables recommends that both names and identification be specified as (source Id_lugar), as the source of the data will be taken into account so as not to combine table information with each other by making mistakes in their relationships.

starting points. Each table has a key attribute to be able to bind to each other, that is, a fundamental feature for consistently relating all of its data. These links are made manually by the user and must contain similar aspects in their attributes in order to have a correct procedure.

Behind each table that is supplied to the program there is its source code, which is the programming behind it to be able to visualize it through its interface in an easy and simple way for use in the company. The program offers us the possibility to contain all the tables by means of diagrams that facilitates the way we want to relate them.

Requirements are a key concept to be able to perform the whole process in the program; they are done by the same user account to follow the steps without wasted time and with everything previously scheduled.

You can make the requirements from a simple document with information in text (non-numeric) [46], where you set the instructions to follow and how to create the system from the database in the program.

The categories that are performed in the program are taken to recognize our key classes, which are the link data and special for your changes if required.

Always the important IDs or codes for a characteristic of a table has to be an obligation key, as it is the only nontransferable reference that will be made of the attribute. In the database you have to follow the priorities of dimensional modeling beforehand because it represents the current situation of the company in reports necessary for the Data 


\section{Warehouse.}

Monthly and annual sales are established in dimensional modeling because of the need to have all the necessary information. Business intelligence requires IDS [47] and other information such as training hours or type of training for business employees.

Sales must carry the time codes that will serve primarily to have the clarity of sales as monthly as annual in the company, and thus account for all sales time. The main table for the entire database is the fact table, which generates the Id_Ventas, and hence specifies that the sales ID is an incremental variable or as required by the company [48].

In the fact table you will have as characteristics all the identifications of time, sale, customer, branch office, product and seller, because it will contain the codes of each attribute of different tables for your successful relationship.

To immediately make relationships in the Data Warehouse, proceed to the "Keys" option, where a window will open with all the tables created; In the tab you will have dropdown lists of each of the tables and will need to contain similar attributes to add in a list by the program [49] itself and thus relate them.

The list of relationships will depend on the need of the business, whether they require a large amount of information in the database in relation to all products and sales, or a smaller amount to represent only sales per time.

The program displays [50] the diagram to check the relationships of each table, so that there is better visibility of information.

\section{Data Mining}

\section{A. Why the mining of information?}

The conservation of the information in the tracers of the years, has been a really important focus for the companies, does that the resultant information of the technological processes is much more robust and interesting, but: for what this information is it so important and the technological processes to treat information, are they so excellent in a company?

To assemble information about a topic in specific with already existing information, it is the principal function of the Byline mining, since this one takes as a principal target to find between thousands of information something that is not coherent or an inconsistency between bosses to give response to any problem that raises, this way, the companies on a global scale, the programs of investigation, the schools, the universities, they will be able to improve many of his processes thanks to the development of mining of information.

\section{B. In the history}

The "Discovery of knowledge in databases" [51] is a term during the tracers of the years it has been called to the process to find different resources of information that in the end join somehow establishing a connection between yes or the prophecy of the tendencies that to future will be really impactites in the humanity. This process is achieved investigating deeply between different types of information and databases that exist already, this way, on the decade of the 90 s one gives him name to the mining of information or dates mining.

Knowing a little of the history of the mining of information, we can proceed to establish the disciplines that compose this process, this way, we will realize well that is a byline mining and the scope of this process thanks to his 3 principal components:

1) Statistics: It is so called

It is defined as a science which takes as a purpose the compilation of information, the order and the analysis of the same ones to fulfill his principal target which is the prophecy and his respective explanation on any gathered fact.

\section{2) Artificial intelligence}

Is defined as the combination of algorithms in order to obtain a decision making that they are as similar as possible to that of the human being, with the purpose of realizing autonomous machines, with the aptitude to decide before a problem, the most viable, sure and effective solution.

\section{3) Machine Learning (automatic Learning)}

Is a science that takes completely autonomous learning as a purpose, in order to identify really complex patterns and to do that a machine has the potential of learning for if alone.

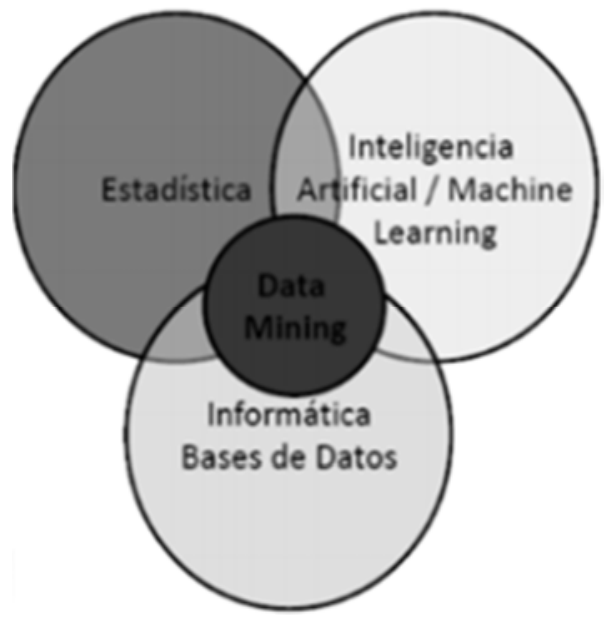

Figure 2. Components.

\section{Traditional methods}

The traditional methods that have been used by a lot of time, are not so effective as the mining of information, since these handle quite wide quantities of information and that, thanks to this, the resultant information of the process, does that it is a quite finished, structured and effective response.

The mining of information or Byline Mining, it is characterized for using patterns, these patterns, they are only methods and already worn-out processes and with which there is obtained a quality of quite wide and effective information.

To use traditional methods:

The traditional processes of mining [52] of information, times behind were much more effective for the quantity of information that was handling in the moment, at present, the 
information that the companies handle be already medium or big, they contain volumes of quite big information and that, if there was used the ancient process of mining of information, this one would take at least a few 10 times more to the process of current mining of information, which is based on the mathematical analysis, in to derive the future tendencies, in the autonomy and efficacy.

\section{Characteristics}

Inside all the characteristics that byline has mining, there exists one that highlights and is it to obtain results without having to realize a specific consultation, classifies all the information of the best way and offers the facility of understanding the results, even this one is quite excellent, his other components are not less important.

\section{1) Be predictive}

Thanks to the big quantity of information with which the mining of information works, it is possible to find information that this one conceals between thousands of files, these with information so important that there allows the process to use statistics and probabilities that were offering a response to the user of something who still does not happen.

\section{2) Response time}

To have an organized set of information and to support it is possible, but to obtain a specific fact that one finds between thousands of information it needs time, the process of mining of information allows to find in a short time the requested $i$

\section{3) Prevent}

The analysis of information, the statistics of the same ones and the arranging that it is possible to obtain, helps the companies to prepare situations that affect the processes, of the same way the productiveness that offers to us the mining of information, it is a true information.

\section{4) Decision making}

To be based on information and statistics for the decision making is a process that any human being and any company should apply, the example of the mining of information is really excellent, because there are always taken decisions that reach port to strategies.

\section{5) Easy understanding}

To have a set of gathered and not organized information is difficult to understand [53], but having organized information that facilitate the understanding of the users in way of report or of consultation, it helps the companies to take assertive decisions that they benefit to the whole labor environment.

\section{E. In what do the companies benefit?}

The companies on a global scale are employed with a big quantity of databases, reports, files between many sources at those that the information preserves, but: how do they control this information?

The mining of information offers to the companies on a global scale a big handling of information, analysis of information, functions predictive and a big autonomy that offers safety and confidence in all the ambiences in those who could apply to themselves these processes, this way, better strategies can develop for the companies, statistics of every activity that is realized by area, between many factors that can be identified to take a plan of action, and the last one, the mining of information has the aptitude to suggest it. The management of the information and the capacity of arranging of the same ones that offers byline mining, contributes in big enough quantities to the fulfillment of audits in the companies.

A factor that must be stood out in the process of mining of information applied to a company, is the rapidity with which the information is obtained, the companies are always working on the time and this process of mining of information is quite attractive for this factor. To look between thousands of information and to obtain a response that is logically good and with a rapid time of response, it is the expectation of thousands of persons every day, but they do not know the current processes that are implemented in the companies, the mining of information must be applied in all the ambiences where one works with information, this helps to the studies investigative, to the processes of study, to the consultation of information in libraries and even to development of new technologies.

\section{$F$. Saving of costs}

Due to the big flow of information with the one that treats the process of mining of information, it needs a big control [54] of these and persons who are always hanging of same, in case a company was not applying the byline mining, the costs would be high enough, since it would be necessary to hire personnel for the achievement of each of the traditional processes and additionally to this, there should to hire personnel that has the capacity of audit the activities that they realize in the clearly traditional processes.

Meanwhile the years they happen, the technology advances, the information and the information every time are bigger, they create to themselves new companies every day, there are realized new investigations that reach port positively to the humanity, to the processes, to the technologies, to the schools and universities, it is important to have a control of everything, to lodge the information in databases, to document all the processes and actions that are realized in a company and especially, to have an easy access to this information likewise to consult and to obtain rapid, agile, true responses and with an analysis previous that facilitates the understanding of every user.

It is much of bearing in mind that the mining of information is a process which allows us to work with the information and likewise to generate a set of processes that they benefit to the companies of all the areas on a global [55] scale, but the byline mining is not a database where the information throws itself, mining of information is to predict information, to generate reports inside the big quantities of information, to increase the efficacy of the processes of the companies thanks to the statistics of information, to improve the selling, to analyze indicators, to control I process of the employees, to meet better the employees, to study in depth specific areas.

\section{G. To the hand of big it dates back}

Big dates allude to big quantities of information, this thrown in databases they have the aptitude to store millions and thousands of millions of these, complex quantities with 
those who can be worked later with the byline mining.

To be more precise, the information with which the mining of information must work is quite big, this way the processes that are realized in the mining of information will be more robust and with more effective information as response to a request or a realized analysis.

Big dates consist of 6 requisites so that this set of information could be called and used this way.
1) SPEED
2) $V O L U M E$
3) VARIETY
4) VERACITY
5) $V A L U E$
6) VALIDITY

The information is the fundamental tool of the byline mining, for end, all the information must be valuable, clear and not repetitive, with this we manage to establish an order in the information and a search most rapid and been ordained as the same one, it is for this characteristic that the Big dates it works of the hand with byline mining, without Big it dates, dates mining it would not be possible.

With this information we can conclude that, to generate statistics, to predict future actions or to analyze processes, valuable information is needed and with quality, that are understandable, should be arranged, variable information and the most important thing, that it is coherent information. When the characteristics [56] are fulfilled mentioned previously, we can guarantee that the process of Byline mining will develop in a most effective way and with excellent results, since one is already provided with a really good and verified source of information.

\section{H. PHASES OF THE MINING OF INFORMATION}

\section{Fases de la minería de datos}

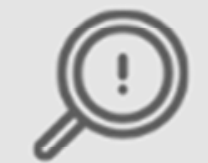

Definir el problema

Identificar los objetivos del negocio.

Identificar el objetivo de la minería de datos

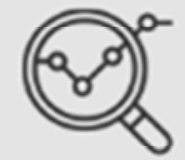

Identificar los datos necesarios

Evaluar los datos necesarios.

Recolectarlos y comprenderlos.
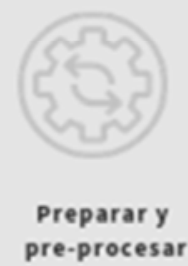

Seleccionar algoritmos.

Limpiar los datos según sea necesario

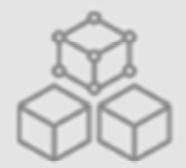

Modelar

los datos

Seleccionar algoritmos.

Construir modelos predictivos

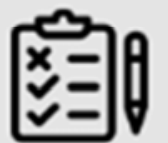

Entrenar $y$ probar

Entrena el modelo con muestra.

Pruebay repetir proceso

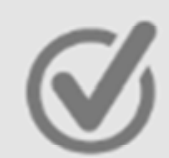

Conocimiento

Verificar el modelo final.

Estudiar las conclusiones

Eunayta

Figure 3. Phases of the mining of information.

To the moment to speak about the phases of the byline mining, we allude to the cycle of life of the same one, each of the steps that are applied for the correct development of this process, the relation in each of the areas that are worked and the specification of every process [57]. It performs big importance to know and to understand each of these processes that they will be highlighted, since this was helping us to fulfill all the requests necessary for the development of mining of information.

1) To define the problem

To initiate the solution of a problem it is important to identify very well to where we want to come and that it is necessary to solve, announcing the problem and the target of the business will be able to follow with the following phase of the byline mining. This phase finishes with the definition and identification of the problem.

2) Identification of the necessary information

The identification of the information that they go away to need for this phase, the process of byline is obtained by the information of the previous point, this way, mining it gathers the information and understands them, giving for this phase finished in the moment in that the information has been evaluated.

3) It prepares and to pre-process

A key point for the mining of information is to select the algorithms that will be necessary to pre-process the activities that are needed on having solved the principal problems, finished this process, inside the same phase there is cleaned the information that are not necessary to work with the cleanest information and to achieve effective responses.

4) To shape information

After having selected algorithms, the shaped one of information consists of giving him a form much cleaner and robust likewise to be able in spite of the fact that models to construct predictive that does of the information a quite valuable resource.

5) To train and to try

This phase takes charge realizing a filter where the model is applied without showing it to the final user, is proved and the finished process repeats itself so that the information is true, robust and predictive [58].

6) Knowledge 
last phase of the process of mining of information, where the model happens once again applied previously to announce it to the final user, also there are studied the conclusions that were appearing as final score be the applied one each of the phases previously mentioned.

\section{To bear in mind}

The creation of companies in all the global areas every time is bigger, thus, the creation of information on a global scale is extraordinary every second, but the most important of the creation of this information is the examination of the same ones. During the development of this chapter, we have demonstrated the importance of having information that are really valuable and the benefits that we can go so far as to obtain with these thanks to the byline mining, the arduous and tidy work that realizes this process of analysis and dealing of information is every more extensive and complex month.

This way we can assure and verify that each of the processes that realizes the byline mining they benefit all the companies that work with enormous quantities of information, doing of these an effective and beneficial tool for the company, improving selling, obtaining new clients [59], improving the efficacy of the employees, reducing costs, between many processes that impacted positively a company.

Meanwhile the technology advances and the traditional methods remain short, owe to create ingenious piece of news of controlling the information and the information that every day is generated, the mining of information is provided with the aptitude to administer correctly this information and to turn them into valuable information for the companies, doing that these are every time better and competent. When a company on a global scale is competent, it is characterized for using methods for the handling of information that are updated and go of the hand with the technology, this way positional much better before the market or the ambience in which these companies develop.

An excellent point for the companies that generate labor competitiveness, is the pleasure of working of the employees, it will always be more gratifying to be employed at competent companies, which reach port positively to the development of the humanity with his goods or services but always with technological responsibility, with efficacy, allegiance to the information and information and although it does not seem important but always it it will be, the handling of technological hardware that they reach port a little in every process, it will be an advance for the company, a technological advance that in turn, it comes with excellent results.

\section{Conclusion}

Having control of information is a key part of being proactive in making [60] decisions and achieving better business control and advantages that differ from the competition and helps make the company's strategy more competitive, supporting decision-making that are vital to better results, greatly facilitating interactivity between users, customers and suppliers, facilitating access to critical company data and corporate [61] information for data integration and decision-making, allows to align actions of different departments and also helps to control each line of business or department.

It is important to understand that decision support tools [62] simplify many operations and processes in the business, but that decision makers are the most important people. Factors that take into account [63], to a greater or lesser degree, such as the speed of change, innovation of new business models, new structures of relationships between companies, their customers and partners, the connectivity of people, organization and countries, and the value of knowledge resident in the company; their knowledge and skills and the use of intelligent decision-making systems [64], and it is the one that generates the competitive advantages between one company and another.

\section{References}

[1] De Mazariegos, A. (May 9, 2004). Information systems for executives. Obtained from gestiopolis: http://www. gestiopolis.com/sistemas-de-information -para-executives/.

[2] Dominguez, J. I. (March 17, 2005). CRM visions. Retrieved from Gestiopolis: http://www.gestiopolis. /4-visiones-crm/.

[3] Zarate, G. (2013). Business intelligence. Obtained from Gestiopolis: $\quad$ http://www.gestiopolis.com/-business intelligence/.

[4] Pentaho.com. (2014). Pentaho Business Analytics. Recuperado de: http://www.pentaho.com/ product/businessvisualization-analytics.

[5] Watson, Hugh J. (2009). Tutorial: Business Intelligence - Past, Present, and Future. Communications of the Association for Information Systems, Vol. 25, Article 39. Recuperado de: http://aisel.aisnet.org/cais/vol25/iss1/39.

[6] Chaudhuri, S., Dayal, U., \& Narasayya, V. (2011). An Overview of Business Intelligence Technology. Communications of the ACM, 54 (8), 88-98. Recuperado de https://cacm.acm.org/magazines/2011/8/114953-an-overviewof-business-intelligence-technology/fulltext.

[7] Snijders, C., Matzat, U., \& Reips, U. D. (2012). 'Big Data': Big gaps of knowledge in the field of Internet. International Journal of Internet Science, 7 (1), 1-5. Recuperado de https://kops.uni-

konstanz.de/bitstream/handle/123456789/28647/Snijders_286 475.pdf? sequence $=2$.

[8] Betts, Mitch. "The future of business intelligence". Computerworld.

http://www.kmcluster.com/The\%20Future\%20of\%20Business $\% 20$ Intelligence.html.

[9] Pavez Salazar, 2000 Pavez Salazar, A. A. (2000). Knowledge management in organizations. Online document. Available in: $\mathrm{http}: / / \mathrm{www}$.gestiondelconocimiento.com/documentos2/apavez /gdc.htm. Retrieved 13 October 2013.

[10] EFQM, 2010 EFQM. European Foundation for Quality Management [consultado 1 Oct 2010]. Disponible en: http://www.efqm.org. 
[11] Claver, E.; Llopis, J.; Lloret, M.; Molina, H.: "Business Administration Manual", $4^{\text {th }}$ Edition, Civitas, Madrid, 2000.

[12] Cyert, R. M.; March, J. G.: "Theory of economic decisions of the comp any", Herrero Hermanos, Mexico, 1965.

[13] Davis, D.: "Management Research for Decision Making", Thomson, Mexico, 2000.

[14] Dixon, J. R.: "Engineering Design: Inventiveness, Analysis and Decision Making", Limusa-Wiley, Mexico, 1970.

[15] Gil Pechuán, I.: "Information Systems and Technologies for Management", Polytechnic University of Valencia, 1996.

[16] Gil Pechuán, I.: "Information Systems for Business Management", Polytechnic University of Valencia, 1994.

[17] González Ramírez, M. R.: "Information Systems for the Company", Publications of the University of Alicante, 2001.

[18] Greenwood, W.: "Theory of Decisions and Information Systems", Trillas, Mexico, 1978.

[19] Herrera, F.; Herrera-Viedma, E.; Verdegay, J. L.: "Direct approach processes in group decision making using linguistic OWA operators", Fuzzy Sets and Systems, 79, 1996, págs. 175-190.

[20] Huber, G. P.: "Management Decision Making", Trillas, Mexico, 1984.

[21] Ernestina Mensalvas Ruiz, José María Peña Sanchez, 2000. Data Mining: Techniques and tools. Polytechnic University of Madrid, Department of Languages and Computer Systems and Software Engineering.

[22] José Martín Arevalillo, 2000. Data Mining, a decision-making tool. U. N. E. D. Department of Statistics and Operational Research.

[23] Areas of Research, Data Warehousing and OLAP Technology in http://gplsi.dlsi.ua.es/gplsi/areas.htm.

[24] Javier Cantoral Justo, 2002. Data Mining Concepts and Techniques. University of Alicante, Research Group of information systems in the company.

[25] Data Mining y Data Warehousing en www.kdnuggets.com.

[26] Data Warehouse Terminology, 2003. En http://www.credata.com/research/terminology.html.

[27] On Line Analitical Processing en http://altaplana.com/olap/.

[28] SENA - National Learning Service (s.f.) ARCHITECTURE OF A DATA BODEGA. Retrieved from https://senaintro.blackboard.com/bbcswebdav/institution/seeds /2172191VIRTUAL/OAAPs/OAAP3/aa4/oaarchitecturebodeg as/utilities/downloadable.pdf.

[29] M. Rizzi S. (2009) Data Warehouse Desing. Modern Principles and Methodologies. Tata McGra-Hill. Recuperado dehttps://cs09lects.files.wordpress.com/2012/12/bookdatawarehouse-design-golfarelli-_-rizzi.pdf.

[30] Castro, Eduardo. (2015). Introduccion datawarehouse. https://es.slideshare.net/ecastrom/introducciondatawarehouse 44384485 .

[31] Ionos - SGBD: introduction to the database management system $\quad-\quad$ March $\quad 03, \quad 20$ https://www.ionos.es/digitalguide/hosting/cuestionestecnicas/sistema-gestor-de-base-de-datos-sgbd/.

[32] Aprende Colombia Aprende - Database Management Systems http://aprende.colombiaaprende.edu.co/sites/default/files/naspublic/ curriculos_ex/n2g10_pweb1/nivel2/web1/unidad1/leccion3.html.

[33] What is a database manager and what is it for? - May 9, 19 https://blog.powerdata.es/el-valor-de-la-gestion-de-datos/quees-un-gestor-de-datos-y-para-que-sirve.

[34] Most used database managers- June 24, 2019 https://www.netec.com/post/que-es-un-gestor-de-base-dedatos-y-cuales-son-los-mas-usados.

[35] Wikipedia - Database management systems https://es.wikipedia.org/wiki/Sistema_de_gesti\%C3\%B3n_de bases_de_datos Concepto.de - What is a database -June 24, 20 - https://concepto.de/base-de-datos/.

[36] 200 Response - Comparison of relational and non-relational databases - October 8, 19 - https://medium.com/200response/comparaci\% $\mathrm{C} 3 \% \mathrm{~B} 3 n$-bases-de-datos-relacionales-yno-relacionales-424dd83dd693.

[37] Academia Progma - Relational databases - May 28, 2019 https://www.pragma.com.co/academia/lecciones/bases-dedatos-relacionales-vs.-norelacionales\#: : text=todos\%201os\%20residentes.-

,Las $\% 20$ bases $\% 20$ de $\% 20$ datos\%20relacionales\%20utilizan $\%$ 20un $\% 20$ lenguaje $\% 20 \mathrm{de} \% 20$ consulta,y $\% 20$ se $\% 20$ almacenan $\% 20$ por $\% 20$ tablas.\&text $=$ afecta $\% 20 \mathrm{a} \% 20$ nadie.-

,Las $\% 20$ bases $\% 20 \mathrm{de} \% 20$ datos\%20no\%20relacionales\%20tie nen $\% 20$ un $\% 20$ esquema $\% 20$ din $\%$ C3\%A1 mico,los $\% 20$ datos $\%$ 20para\%20su\%20manipulaci\%C3\%B3n.

[38] PowerData - Types and function of database managers August 12, 2015 - https://blog.powerdata.es/el-valor-de-lagestion-de-datos/bid/406547/tipos-y-funci-n-de-los-gestoresde-bases-de-datos.

[39] FreelancerMap - What does a database administrator do? June 17, $2020 \mathrm{https} / / / \mathrm{www}$.freelancermap.com/blog/es/que-haceadministrador-bases-datos/.

[40] The Web Logic, (2017), Youtube "Business Intelligence How to create a Data Warehouse." https://www.youtube.com/watch?v=WAOs7E0xXZk.

[41] Alejandro P, (2015), YouTube "Introducción a Data Warehouses". https://www.youtube.com/watch?v=R9XZavDU-9M.

[42] Logicalis, (2016) "Business Intelligence Tools". https://blog.es.logicalis.com/analytics/herramientas-businessintelligence-tendencias-2017.

[43] Synergy, (website), "Architecture of a Business Intelligencesolution".

https://www.sinnexus.com/business_intelligence/arquitectura. aspx.

[44] DeepenU5, (PDF Document),"Layers of all architecture of a Datawarehouse".

https://virtual.cun.edu.co/contenidos/migracion2020/sistemas/ s9/business-intelligence/u5/recurso5.pdf.

[45] Power Data. (2016). The value of data management. What you need to know about the architecture of a datawarehousehttps://blog.powerdata.es/elvalor-de-la-gestionde-datos/lo-que-necesitassaber-acerca-de-la-arquitectura-deundatawarehouse. 
[46] NSU, (2019), (web magazine), "Handling and Using Metadata for Files: Comparative Analysis of Major Models and Standards".

http://www.nosolousabilidad.com/articulos/manejo_y_uso_de _los_metadatos_para_archivos.htm.

[47] European Union (2004). Commission Decision 2004/387/EC of 28 April 2004 - Decision 2004/387/EC of the European Parliament and of the Council of 21 April 2004 on the interoperable provision of Pan-European e-government services to the public sector, businesses and citizens (IDABC). Recovered from http://eur-lex.europa.eu/legalcontent/ES/TXT/?uri=OJ:L:2004:144:TOC.

[48] Van Ballegooie, M., Duff, W. (2006). DCC Digital Curation Manual: Instalment on Archival Metadata. Recuperado de http://www.dcc.ac.uk/sites/default/files/documents/resource/c uration-manual/chapters/archival-metadata/archivalmetadata.pdf.

[49] OrganizesU5, (PDF Document), "Datawarehouse Layers". https://virtual.cun.edu.co/contenidos/migracion2020/sistemas/ s9/business-intelligence/u5/recurso7.pdf.

[50] P. N. Roldan, "That is the statistics", Ecnomipedia, https://economipedia.com/definiciones/estadistica.html.

[51] Lugo. A. (2020). ¿What is the intelligence of Business? INVID. Recovered of: https://invidgroup.com/es/que-es-lainteligencia-de-negocios/.

[52] Syloper. (2018). ¿Why does it serve the mining of information does its date mining? [Online]. Available: https://www.syloper.com/blog/recursos/para-que-sirve-lamineria-de-datos/.

[53] R. Gallard, "Extraction of Knowledge in Big Databases Using strategies adaptive", Doctoral dissertation, University of the silver, / Buenos Aires, Argentina marsh de 2012. Available: http://sedici.unlp.edu.ar/bitstream/handle/10915/35555/Docu mento_completo.pdf?sequence=1.
[54] Lopez. A. Joaquin. (2019). Data mining - Economipedia. Recovered of: https://economipedia.com/definiciones/mineriade-datos.html.

[55] National university of México. (marsh del 2016). Intelligence of Business: strategy for the development of the competitiveness in companies of technological base. ScienceDirect. Recovered of: https://www.sciencedirect.com/science/article/pii/S018610421 5000807.

[56] Golive. (2019). ¿What is the intelligence of business? GOLIVE. Recovered of: https://www.onegolive.com/faq/guiapractica-de-inteligencia-de-negocio/que-es-inteligencia-denegocio/.

[57] Oracle. (2016). What is the intelligence of business? Recovered of: https://www.oracle.com/ocom/groups/public/@otn/documents /webcontent/317529_esa.pdf.

[58] A. Gonzalez. (2016). ¿What is Machine Learning? [Online]. Available: https://cleverdata.io/que-es-machine-learning-bigdata/\#: :text=Machine\%20Learning\%20es\%20una\%20discipl ina,complejos $\% 20 \mathrm{en} \% 20$ millones $\% 20 \mathrm{de} \% 20$ datos.

[59] Iberdrola. (2018) What is the artificial intelligence? [Online]. Available: https://www.iberdrola.com/innovacion/que-esinteligencia-artificial.

[60] Andrés. Q. (2021). "That it's business intelligence" and "Information Systems in Decision Making".

[61] Jhon. B. (2021). "DataMining".

[62] Leyder. C. (2021). "DataWareHouse".

[63] David. R. (2021). "Database Manager Systems".

[64] Felipe. M. (2021). "Data WareHouse Covers". 